\title{
Preparation of the Dräger Primus anesthetic machine for malignant hyperthermia-susceptible patients
}

\author{
[La préparation de l'appareil à anesthésie Dräger Primus pour les patients suscep- \\ tibles d'byperthermie maligne]
}

Heike Prinzhausen FrCA, Mark W. Crawford MBBS FRCPC, James O'Rourke MBBCh FFARCSI, Guy C. Petroz MD

Purpose: Preparation of anesthesia machines for patients who are susceptible to malignant hyperthermia includes flushing the machine with vapour-free fresh gas to washout residual anesthetic agents. To establish guidelines for the preparation of the Dräger Primus machine, we compared the washout profiles for isoflurane and sevoflurane in the Dräger Primus and Ohmeda Excel 210 anesthesia machines.

Technical features: The machines were primed with $1.5 \%$ isoflurane or $2.5 \%$ sevoflurane. Fresh gas flow (FGF) was set at $10 \mathrm{~L} \cdot \mathrm{min}^{-1}$ during the early washout phase, and subsequently reduced to $3 \mathrm{~L} \cdot \mathrm{min}^{-1}$ during the late washout phase. A Miran ambient air analyzer measured the anesthetic concentration every minute during washout until a concentration of $5 \mathrm{ppm}$ was achieved in the inspiratory limb of the circle circuit. We found that at a FGF of $10 \mathrm{~L} \cdot \mathrm{min}^{-1}$, maximum washout times for isoflurane and sevoflurane in the Primus, 70 and $74 \mathrm{~min}$, respectively, were approximately tenfold greater than for isoflurane in the Excel $210(7.0 \mathrm{~min})$. Increasing the FGF to $18 \mathrm{~L} \cdot \mathrm{min}^{-1}$ decreased the washout time for isoflurane in the Primus, only moderately, to $52 \mathrm{~min}$. We observed a threefold increase in anesthetic concentration in the Primus during the late washout phase.

Conclusion: We conclude that the Primus must be flushed for at least $70 \mathrm{~min}$ to decrease the anesthetic concentration to 5 ppm when using a FGF of $10 \mathrm{~L} \cdot \mathrm{min}^{-1}$. We recommend maintaining a FGF of $10 \mathrm{~L} \cdot \mathrm{min}^{-1}$ for the duration of anesthesia in order to prevent the rebound increase in anesthetic concentration in the FGF.
Objectif: La préparation des appareils à anesthésie pour les patients susceptibles d'hyperthermie maligne comprend la purge de l'appareil avec des gaz frais sans vapeur pour éliminer les anesthésiques résiduels. Nous avons comparé les profils d'élimination de l'isoflurane et du sévoflurane des appareils à anesthésie Dräger Primus et Ohmeda Excel 210 pour établir des lignes directrices concernant la préparation de l'appareil Dräger Primus.

Éléments techniques: Une purge des appareils a été faite avec de l'isoflurane à $I, 5 \%$ ou du sévoflurane à $2,5 \%$. Le débit de gaz frais (DGF), fixé à $10 \mathrm{~L} \cdot \mathrm{min}^{-1}$ pour la première phase de purge, a été réduit à $3 \mathrm{~L} \cdot \mathrm{min}^{-1}$ pendant la dernière phase. Un analyseur d'air ambiant Miran donnait la concentration d'anesthésique à chaque minute pendant la purge jusqu'à l'obtention d'une concentration de 5 ppm dans la branche inspiratoire du circuit fermé. À un DGF de $10 \mathrm{~L} \cdot \mathrm{min}^{-1}$, le temps de purge maximal de 70 et de $74 \mathrm{~min}$ dans le Primus pour l'isoflurane et le sévoflurane respectivement était environ dix fois plus long que pour l'isoflurane dans le Excel 210 (7,0 min). L'augmentation du DGF à I $8 \mathrm{~L} \cdot \mathrm{min}^{-1}$ a diminué le temps de purge pour l'isoflurane dans le Primus, mais modérément à 52 min. Une augmentation trois fois plus importante de la concentration anesthésique a été observée dans le Primus pendant la dernière phase de la purge.

Conclusion: Le Primus doit être purgé pendant au moins 70 min pour y faire baisser la concentration anesthésique à 5 ppm avec un DGF à $10 \mathrm{~L} \cdot \mathrm{min}^{-1}$. Nous recommandons de maintenir un DGF à $10 \mathrm{~L} \cdot \mathrm{min}^{-1}$ pour la durée de l'anesthésie afin de prévenir l'augmentation par rebond de la concentration d'anesthésique dans les gaz frais.

From the Department of Anesthesia, The Hospital for Sick Children, University of Toronto, Toronto, Ontario, Canada. Address correspondence to: Dr. Crawford, Department of Anesthesia, The Hospital for Sick Children, 555 University Avenue, Toronto, Ontario M5G 1X8, Canada. Phone: 416-813-6466; Fax: 416-813-7543; E-mail: mark.crawford@sickkids.ca

Support was provided from departmental sources.

Presented in part at the annual meeting of the American Society of Anesthesiologists in Atlanta, October 26, 2005.

Accepted for publication April 6, 2006.

Revision accepted May 17, 2006.

Competing interests: None declared. 
$\mathrm{M}$ ALIGNANT hyperthermia $(\mathrm{MH})$, a potentially lethal inherited metabolic disorder, can be triggered by inhalational anesthetic agents. Guidelines for the preparation of anesthetic machines for use in patients who are $\mathrm{MH}$-susceptible include flushing the machine with vapour-free fresh gas to washout residual inhalational anesthetic agents. A ten-minute flush at a fresh gas flow (FGF) of $10 \mathrm{~L} \cdot \mathrm{min}^{-1}$ is commonly used in clinical practice. ${ }^{1}$ This guideline is based on data derived from older style anesthetic machines such as the Ohmeda Excel 210 (GE Healthcare, Helsinki, Finland). The internal circuitry of new generation anesthesia machines is relatively complex and contains plastic and rubber components that can absorb and subsequently release anesthetic vapour. ${ }^{2,3}$ For such anesthesia machines, effective flushing can require considerably longer than ten minutes. ${ }^{4}$ In the present study, we evaluated the washout profiles for isoflurane and sevoflurane in the Primus anesthetic machine (Dräger, Lübeck, Germany) in order to establish guidelines for the preparation of this machine for $\mathrm{MH}$-susceptible patients. For comparison, we also evaluated the washout of isoflurane in the Excel 210.

\section{Methods}

We divided our study into four parts. In Part 1, we compared the washout profiles for isoflurane in the Primus and the Excel 210 anesthetic machines. Four Primus and two Excel 210 anesthetic machines were each studied in triplicate. All machines were primed for two hours with $1.5 \%$ isoflurane in air at a FGF of $2 \mathrm{~L} \cdot \mathrm{min}^{-1}$. This was achieved using a circle breathing circuit, a test lung, and controlled ventilation with a tidal volume of $500 \mathrm{~mL}$ and a respiratory rate of 15 breaths. $\mathrm{min}^{-1}$ (minute ventilation, $7.5 \mathrm{~L} \cdot \mathrm{min}^{-1}$ ). On completion of priming, the vaporizer was removed from the machine, and the carbon dioxide absorber, circle circuit, and test lung were replaced with components that had not been exposed to inhalational anesthetics. In the Excel 210, we replaced the ventilator bellows and ventilator tubing as well.

To determine the washout profile for isoflurane, the FGF was set initially at $10 \mathrm{~L} \cdot \mathrm{min}^{-1}$ and the concentration of isoflurane in the inspiratory limb of the circle circuit was measured every minute (early washout phase). When the concentration of isoflurane in the inspiratory limb reached $5 \mathrm{ppm}$, the FGF was reduced to $3 \mathrm{~L} \cdot \mathrm{min}^{-1}$ to simulate a clinically relevant flow during anesthesia (late washout phase). Thereafter, the concentration of isoflurane in the inspiratory limb was measured every minute for an additional hour or until the concentration reached $5 \mathrm{ppm}$ again. During the washout phases, a Miran SapphIRe 205B series portable ambient air analyzer (Thermo Electron Corporation, Waltham, MA, USA) was used to measure the concentration of isoflurane. This device is able to measure a wide range of chemical substances including anesthetic vapours using infrared spectroscopy. It has an accuracy of $5 \%$ and a sensitivity of 0.1 $\mathrm{ppm}$. We calibrated the analyzer outside the operating room prior to each experiment.

In Part 2 of the experiment, we evaluated the washout profile for sevoflurane in the Primus anesthetic machine. Four Primus machines were studied in triplicate. We primed the machines for two hours with 2.5\% sevoflurane to simulate a clinically relevant concentration. All settings during priming were the same as in Part 1 of the experiment. At completion of priming, the vaporizer was removed, and the carbon dioxide absorber, circle circuit, and test lung were replaced with components that had not been exposed to inhalational anesthetics. The early and late washout phases were conducted as in Part 1 , and the concentration of sevoflurane in the inspiratory limb of the circle circuit was recorded every minute.

In Part 3, we evaluated the effect of FGF on the washout of isoflurane. Four Primus machines were studied in triplicate. The machines were primed, and the components replaced after priming as in Part 1. Fresh gas flows of $18 \mathrm{~L} \cdot \mathrm{min}^{-1}$ and $10 \mathrm{~L} \cdot \mathrm{min}^{-1}$ were used during the early and late phases of the washout, respectively, and minute ventilation was kept constant at $7.5 \mathrm{~L} \cdot \mathrm{min}^{-1}$.

In Part 4, we evaluated the effect of minute ventilation on the washout of isoflurane in four Primus anesthetic machines. Components were replaced after priming as in Part 1 . A minute ventilation of $15 \mathrm{~L} \cdot \mathrm{min}^{-1}$ (tidal volume, $500 \mathrm{~mL}$; rate, 30 breaths $\mathrm{min}^{-1}$ ) was used during washout, with FGFs of $10 \mathrm{~L} \cdot \mathrm{min}^{-1}$ and 3 $\mathrm{L} \cdot \mathrm{min}^{-1}$ during the early and late phases, respectively. Experimental conditions are summarized in Table I.

Data are reported as mean $\pm \mathrm{SD}$. The MannWhitney rank-sum test was used to compare washout times. This test, rather than its parametric equivalent, was used because of between-group differences in variances. A Bonferroni correction was applied for multiple comparisons. $P<0.05$ was considered statistically significant.

\section{Results}

In Part 1 , isoflurane concentration decreased exponentially during the early phase of the washout, reaching $5 \mathrm{ppm}$ in a maximum of $70 \mathrm{~min}(63.6 \pm 5.1 \mathrm{~min})$ in the Primus (Figure 1). Isoflurane concentration decreased approximately tenfold faster in the Excel 


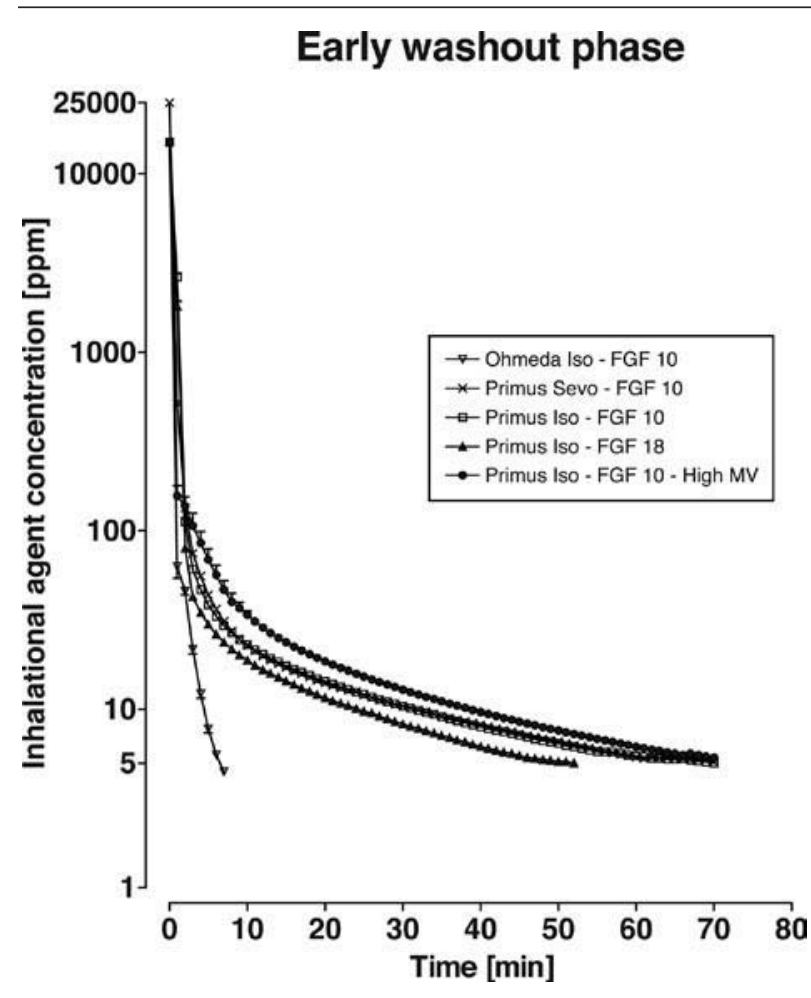

FIGURE I Early washout profiles for isoflurane (Iso) and sevoflurane (Sevo) in the Primus and Ohmeda Excel 210. At a fresh gas flow (FGF) of $10 \mathrm{~L} \cdot \mathrm{min}^{-1}$ (FGF 10), isoflurane and sevoflurane concentrations decreased exponentially, reaching $5 \mathrm{ppm}$ in a maximum of $70 \mathrm{~min}$ and $74 \mathrm{~min}$, respectively, compared with a tenfold faster washout in the Excel $210(7 \mathrm{~min})(P<0.0001)$. At a FGF of $18 \mathrm{~L} \cdot \mathrm{min}^{-1}$ (FGF 18), the washout of isoflurane in the Primus was only marginally faster, reaching $5 \mathrm{ppm}$ in a maximum of $52 \mathrm{~min}$. Doubling the minute ventilation had no significant effect on the washout of isoflurane (FGF 10 - high minute ventilation). Data are mean $\pm S D$. MV $=$ minute ventilation.

210 , reaching $5 \mathrm{ppm}$ in a maximum of seven minutes $(6.7 \pm 0.5 \mathrm{~min})(P<0.0001)$. During the late phase of the washout, we observed a rebound increase in isoflurane concentration in the inspiratory limb of the circle circuit (Figure 2). In the Primus, isoflurane concentration increased approximately threefold to 15.6 $\pm 0.9 \mathrm{ppm}$ during the late phase of the washout and decreased slowly thereafter, remaining above $5 \mathrm{ppm}$ for the duration of the experiment. In the Excel 210, isoflurane concentration increased to $8.4 \pm 0.4 \mathrm{ppm}$ during the late phase of the washout, returning to 5 ppm within $20.0 \pm 6.0 \mathrm{~min}$.

In Part 2, the washout of sevoflurane during the early and late phases in the Primus was almost identi-

\section{Late washout phase}

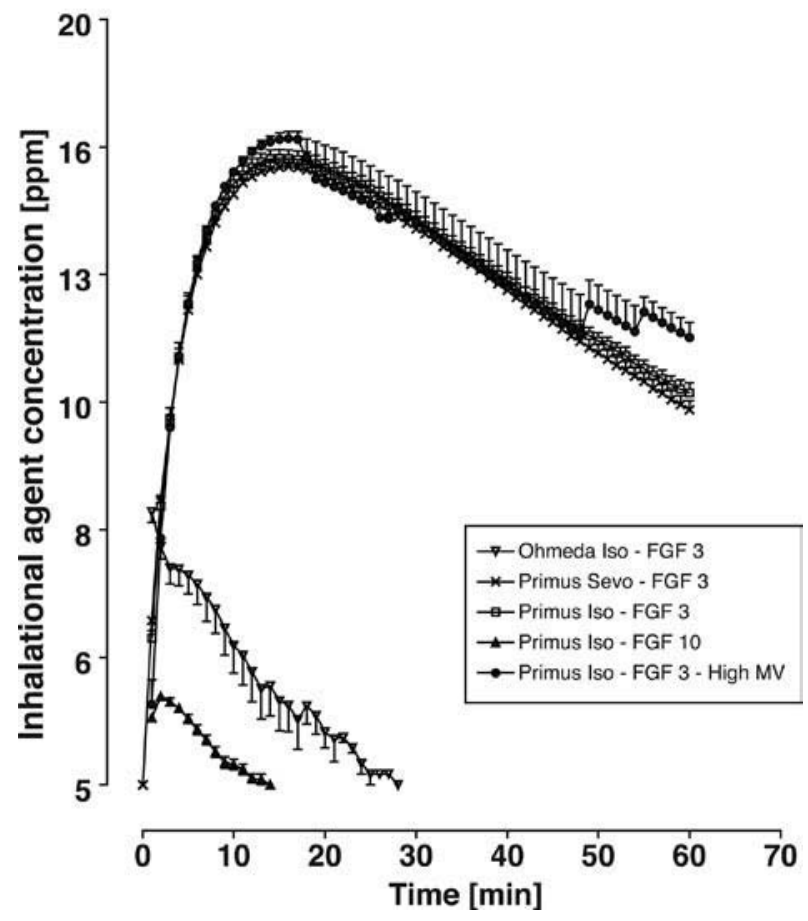

FIGURE 2 Late washout profiles for isoflurane (Iso) and sevoflurane (Sevo) in the Primus and Ohmeda Excel 210. When the fresh gas flow (FGF) was reduced from $10 \mathrm{~L} \cdot \mathrm{min}^{-1}$ to $3 \mathrm{~L} \cdot \mathrm{min}^{-1}(\mathrm{FGF} 3)$ or from $18 \mathrm{~L} \cdot \mathrm{min}^{-1}$ to $10 \mathrm{~L} \cdot \mathrm{min}^{-1}(\mathrm{FGF}$ 10 ), we observed a rebound increase in the vapour concentration in the FGF, the greatest being a threefold increase in anesthetic concentration in the Primus. Doubling the minute ventilation had no significant effect on the washout of isoflurane (FGF 3 - high minute ventilation). Data are mean \pm SD. $\mathrm{MV}=$ minute ventilation .

cal to that for isoflurane (Figures 1 and 2). During the early phase, sevoflurane concentration decreased exponentially, reaching $5 \mathrm{ppm}$ in a maximum of 74 $\min (64.6 \pm 4.3 \mathrm{~min})$. As for isoflurane, an approximate threefold increase in sevoflurane concentration was observed during the late washout phase, reaching $15.3 \pm 0.8 \mathrm{ppm}$ and then decreasing, but remaining above $5 \mathrm{ppm}$ for the remainder of the experiment.

In Part 3, increasing the FGF to $18 \mathrm{~L} \cdot \mathrm{min}^{-1}$ accelerated the washout of isoflurane in the Primus only moderately (Figure 1) $(P<0.0001)$; the washout time was still eightfold greater than that in the Excel 210 $(P<0.0001)$. During the early phase of the washout, isoflurane concentration decreased exponentially, 
TABLE I Experimental conditions

\begin{tabular}{llll}
\hline & Anesthetic agent & FGF & Minute ventilation \\
& & Early washout phase & Late washout phase \\
\hline Part 1 - Isoflurane & Isoflurane & $10 \mathrm{~L} \cdot \mathrm{min}^{-1}$ & $3 \mathrm{~L} \cdot \mathrm{min}^{-1}$ \\
Part 2 - Sevoflurane & Sevoflurane & $10 \mathrm{~L} \cdot \mathrm{min}^{-1}$ & $3 \mathrm{~L} \cdot \mathrm{min}^{-1}$ \\
Part 3 - Effect of FGF & Isoflurane & $18 \mathrm{~L} \cdot \mathrm{min}^{-1}$ & $10 \mathrm{~L} \cdot \mathrm{min}^{-1}$ \\
Part 4 - Effect of minute ventilation & Isoflurane & $10 \mathrm{~L} \cdot \mathrm{min}^{-1}$ & $7.5 \mathrm{~L} \cdot \mathrm{min}^{-1}$ \\
\hline
\end{tabular}

FGF $=$ fresh gas flow.

TABLE II Washout characteristics

\begin{tabular}{|c|c|c|c|}
\hline & \multirow{2}{*}{$\begin{array}{l}\text { Early washout phase } \\
\text { Time to } 5 \text { ppm (min) }\end{array}$} & \multicolumn{2}{|c|}{ Late washout phase } \\
\hline & & Peak (ppm) & Time to $5 \mathrm{ppm}$ ( $\mathrm{min}$ ) \\
\hline \multicolumn{4}{|l|}{ Part I - Isoflurane } \\
\hline Dräger Primus & $63.6 \pm 5.1$ & $15.6 \pm 0.9$ & $>60 *$ \\
\hline Ohmeda Excel 210 & $6.7 \pm 0.5^{* *}$ & $8.4 \pm 0.4$ & $20.0 \pm 6.0$ \\
\hline \multicolumn{4}{|l|}{ Part 2 - Sevoflurane } \\
\hline Dräger Primus & $64.6 \pm 4.3$ & $15.3 \pm 0.8$ & $>60 *$ \\
\hline \multicolumn{4}{|l|}{ Part 3 - Effect of FGF } \\
\hline Dräger Primus & $48.6 \pm 2.7^{* *}$ & $5.9 \pm 0.1$ & $11.1 \pm 1.7$ \\
\hline \multicolumn{4}{|c|}{ Part 4 - Effect of minute ventilation } \\
\hline Dräger Primus & $71.5 \pm 5.4$ & $16.1 \pm 0.4$ & $>60 *$ \\
\hline
\end{tabular}

Data are mean $\pm \mathrm{SD} . \mathrm{FGF}=$ fresh gas flow. ${ }^{*}$ Did not reach $5 \mathrm{ppm}$ within one hour. ${ }^{*} P<0.0001$ compared with corresponding value for Dräger Primus Part 1.

reaching 5 ppm in a maximum of $52 \min (48.6 \pm$ $2.7 \mathrm{~min})$ in the Primus. During the late phase of the washout, isoflurane concentration increased to only $5.9 \pm 0.1 \mathrm{ppm}$, returning to $5 \mathrm{ppm}$ within $11 \pm 1.7$ min (Figure 2).

In Part 4, doubling the minute ventilation had no effect on the washout time for isoflurane (Figure 1). At a minute ventilation of $15 \mathrm{~L} \cdot \mathrm{min}^{-1}$, isoflurane concentration decreased exponentially during the early washout phase, reaching $5 \mathrm{ppm}$ in a maximum of $77 \mathrm{~min}$ $(71.5 \pm 5.4 \mathrm{~min})$ in the Primus. The rebound increase in isoflurane concentration during the late washout phase was similar to that observed in Part 1 (Figure 2). Washout times are summarized in Table II.

\section{Discussion}

The results show that washout times were approximately tenfold greater for the Primus than for the Excel 210 under the conditions of the current study. Maximum anesthetic washout time was $70 \mathrm{~min}$ or greater in the Primus and decreased only to $52 \mathrm{~min}$ when the FGF was increased to $18 \mathrm{~L} \cdot \mathrm{min}^{-1}$. Even at a FGF of $18 \mathrm{~L} \cdot \mathrm{min}^{-1}$, the washout time for isoflurane was approximately fivefold greater than the ten-minute flush recommended in some current guidelines. ${ }^{l}$ In addition, we noted a threefold increase in anesthetic concentration in the Primus when the FGF was reduced to a clinically relevant rate during the late washout phase. A similar increase in anesthetic concentration has been reported previously for the Siemens Kion anesthesia machine ${ }^{4}$ (Siemens Elema, Solona, Sweeden).

The greater washout time and the rebound increase in anesthetic concentration in the Primus may be attributed to several factors. First, the internal circuitry of the Primus is compartmentalized, ${ }^{5}$ resulting in complex gas flow dynamics and the potential for residual pockets of fresh gas containing relatively high concentrations of anesthetic vapour that can be flushed out only slowly. Second, the internal circuitry consists in part of non-exchangeable plastic and rubber components. Inhalational anesthetics dissolve into and subsequently elute slowly from these components. ${ }^{2,3}$ Third, to prevent dependency of tidal volume on FGF, the Primus utilizes a principle referred to as fresh gas decoupling, 5 in which the ventilator and the inspiratory part of the internal circuitry are decoupled from the fresh gas unit in inspiration. Thus, fresh gas passes to the manual ventilation bag via the carbon dioxide absorber in inspiration, and is subsequently fed directly into the breathing system together with the stored volume via a non-return valve (fresh gas decoupling valve) in expiration. Accordingly, the inspiratory part of the internal circuitry is flushed only intermittently during the respiratory cycle. The relative importance of these factors remains to be established. 
Previous studies evaluating the washout profiles of inhalational anesthetics in other anesthesia machines have used various priming concentrations, measurement techniques, FGFs, and concentration endpoints. ${ }^{4,6-9}$ We used a priming concentration of $1.5 \%$ for isoflurane and $2.5 \%$ for sevoflurane in order to evaluate these volatile agents at clinically relevant concentrations. We measured anesthetic concentrations using a Miran SapphIRe 205B series portable ambient air analyzer, which uses infrared spectroscopy and has a sensitivity of $0.1 \mathrm{ppm}$. This method of analysis has the advantage over other previously used methods such as gas chromatography of being able to measure anesthetic concentration within the breathing circuit contemporaneously. During the early washout phase of the experiment, we studied the effect of two different FGF rates on the washout of anesthetic vapour. The first, $10 \mathrm{~L} \cdot \mathrm{min}^{-1}$, is commonly used in clinical practice. ${ }^{1}$ The second, $18 \mathrm{~L} \cdot \mathrm{min}^{-1}$, is the maximum FGF that can be delivered by the Primus machine. In addition, because the fresh gas decoupling mechanism limits flushing of the internal inspiratory circuit to specific times in the respiratory cycle, we studied the effect of minute ventilation on washout. Our results suggest that increasing neither FGF nor minute ventilation has a clinically relevant effect on the washout of inhalational anesthetics from the Primus.

During the early washout phase of the experiment, we flushed the anesthetic machines until the concentration in the breathing circuit reached $5 \mathrm{ppm}$. Previous authors have used endpoint concentrations ranging from $1 \mathrm{ppm}$ to $10 \mathrm{ppm} .{ }^{4,6,7,9}$ The minimum concentration of inhalational anesthetic needed to trigger an $\mathrm{MH}$ reaction in humans is unknown and will probably remain unknown because it would be unethical to expose $\mathrm{MH}$-susceptible patients to inhalational anesthetics; however, evidence suggests that $\mathrm{MH}$-susceptible swine do not develop $\mathrm{MH}$ when exposed to $5 \mathrm{ppm}$ of halothane. ${ }^{\mathrm{A}}$ Additionally, ambient operating room anesthetic concentrations were frequently in the range of 1 to $5 \mathrm{ppm}$ before gas scavenging became standard in the operating room, and to our knowledge there are no reports of $\mathrm{MH}$ reactions in health care workers exposed to the operating room environment. Considering those facts, we chose a vapour concentration of $5 \mathrm{ppm}$ as a valid measurement endpoint. If an endpoint of $10 \mathrm{ppm}$ is considered, the flush time for the Primus at a FGF of

A Maccani RM, Wedel DJ, Kor TM, Joyner MJ, Johnson ME, Hall $B A$. The effect of trace halothane exposure on triggering malignant hyperthermia in susceptible swine. Anesth Analg 1996; 82: S287.
$10 \mathrm{~L} \cdot \mathrm{min}^{-1}$ is $34 \mathrm{~min}$, compared with $25 \mathrm{~min}$ for the Siemens Kion. ${ }^{4}$

In summary, to prepare the Primus anesthetic machine for use in $\mathrm{MH}$-susceptible patients, the machine must be flushed for at least $70 \mathrm{~min}$ to achieve an anesthetic concentration of $5 \mathrm{ppm}$ when using a FGF rate of $10 \mathrm{~L} \cdot \mathrm{min}^{-1}$. We recommend maintaining a FGF of $10 \mathrm{~L} \cdot \mathrm{min}^{-1}$ throughout the duration of anesthesia in order to prevent an increase in anesthetic concentration in the FGF. Increasing the FGF or minute ventilation is of limited clinical value in accelerating anesthetic washout from the Primus anesthetic machine. In addition, we recommend that guidelines for the preparation of anesthetic machines for $\mathrm{MH}$ susceptible patients should be specific for each type of machine. Alternatively, a dedicated vapour-free anesthesia machine may be used for $\mathrm{MH}$-susceptible patients.

\section{Acknowledgements}

The authors thank the Occupational Health and Safety Services, The Hospital for Sick Children, Toronto, for their generous loan of the Miran SapphIRe 205B Series Portable Ambient Air Analyzer. We gratefully acknowledge the technical assistance of $\mathrm{Mr}$. Keith Mathews, RTT, Department of Anesthesia, and Mr. Rocky Yang, BASc, Department of Medical Engineering.

\section{References}

1 Malignant Hyperthermia Association of the United States. Available from URL; www.mhaus.org (accessed May 8, 2006).

$2 \operatorname{Targ} A G$, Yasuda N, Eger EI II. Solubility of I-653, sevoflurane, isoflurane, and halothane in plastics and rubber composing a conventional anesthetic circuit. Anesth Analg 1989; 69: 218-25.

3 Eger EI II, Larson CP Jv, Severinghaus JW. The solubility of halothane in rubber, soda lime and various plastics. Anesthesiology 1962; 23: 356-9.

4 Petroz GC, Lerman J. Preparation of the Siemens KION anesthetic machine for patients susceptible to malignant hyperthermia. Anesthesiology 2002; 96: 941-6.

5 Primus Anesthetic Workstation User Manual, $1^{\text {st }}$ ed. Drager Medical AG; 2003.

6 Beebe JJ, Sessler DI. Preparation of anesthesia machines for patients susceptible to malignant hyperthermia. Anesthesiology 1988; 69: 395-400.

7 Ritchie PA, Cheshire MA, Pearce NH. Decontamination of halothane from anaesthetic machines achieved by continuous flushing with oxygen. Br J Anaesth 1988; 60: 859-63. 
8 McGraw TT, Keon TP. Malignant hyperthermia and the clean machine. Can J Anaesth 1989; 36: 530-2.

9 Schönell LH, Sims C, Bulsara M. Preparing a new generation anaesthetic machine for patients susceptible to malignant hyperthermia. Anaesth Intensive Care 2003; 31: 58-62. 